\title{
A Palavra escrita: entre a lei e a marginalidade
}

\author{
Ivete Lara Camargos Walty*
}

\begin{abstract}
Resumo
Em pesquisa sobre a literatura produzida por prisioneiros políticos e comuns, tenho procurado responder às seguintes questões: Como se delineia a prisão nas escritas em primeira pessoa na literatura brasileira e quebequense da contemporaneidade? Como se relacionam, nessas escritas, a instituição prisional e as demais instituições: Família, Escola, Igreja, Estado, face à questão da violência? Como se desenha o corpo na escrita em sua relação com essa violência? Como se conjugam subjetividade e coletividade na figuração dos sujeitos narrativos envolvidos? Como se associam estética, ética e política na escrita da prisão? No presente trabalho, analiso os livros Memórias de um sobrevivente, de Luís Alberto Mendes, Bienvenu dans mon cauchemar e Lettres de prison, de Marie Gagnon, observando, sobretudo, o papel da escrita na situação-limite entre a marginalidade e a lei.
\end{abstract}

Palavras-chave: Escrita. Prisão. Corpo. Subjetivação. Lei. Marginalidade.

\section{The Written Word: Between The Law and The Marginality}

\begin{abstract}
In a research on the literature produced by political and common prisoners, I am trying to answer the following questions: How is the prison described in the contemporary firstperson narrator from Brazilian and Québécois literatures? How is the prison, in these writings, associated to other institutions, i.e., family, school, church, state, in relation to the violence issue? How is the body described in these writings in its relation with violence? How are subjectivity and collectiveness conjugated in the figuration of the involved narrative subjects? How are ethics, aesthetics and politics conjugated in the prison writings? In this work, I analyze the books Memórias de um Sobrevivente, by Luís Alberto Mendes, and Bienvenu dans mon cauchemar and Lettres de prison, by Marie Gagnon, observing, specially, the importance of writing in a limit situation between marginality and law.
\end{abstract}

Keywords: Writing. Prison. Body. Subjectivation. Law. Marginality

Recebido: 15/03/2018

Aceito: 25/03/2018

\footnotetext{
* Pontifícia Universidade Católica de Minas Gerais (PUC Minas). Professora do Programa de pós-graduação em Letras. Pesquisadora do CNPq.
} 


\section{Da tortura ao corpo abjeto}

Eu sou um filho da puta! Não precisa editar (risos). Sou um filho da puta. Sou um angustiado e a única satisfação que eu encontro na vida é escrever. Quando escrevo um texto bonito, lógico, que acredito e gosto, eu realmente me sinto feliz. Só nesse momento eu sou feliz. (Luiz Alberto Mendes, entrevista em Livre opinião. Ideias em debate)

Luiz Alberto Mendes, prisioneiro brasileiro desde os anos 1970, escreveu suas memórias de vida na prisão, Memórias de um sobrevivente (2009) e as publicou em 2001, ainda na prisão, onde permaneceu por mais de trinta anos. Constituindo uma trilogia, publicou também Às cegas (2005) e Confissões de um homem livre (2015), pela prestigiada Editora Companhia das Letras. Em seu primeiro livro, escrito na prisão, volta-se para suas vivências desde a infância em família pobre, marcada pela violência do pai e pela doçura da mãe. A narrativa conta, em espiral, o ciclo vicioso de violência sofrida e exercida. Sofrida por ele nas surras do pai, nas disputas com outros presos e nas torturas praticadas pelos agentes policiais. Exercida por ele em pequenos roubos de punguista, batedor de carteiras, no centro da cidade de São Paulo ou em grandes assaltos a lojas e postos de gasolina, e ainda nos embates com a polícia e com outros presos. Entre os assaltos, os aprisionamentos; entre os aprisionamentos, assaltos, sexo, droga e rock and roll. Nesse movimento circular em que bandidos e policiais trocam de papel na medida em que aqueles são explorados por estes, que, por sua vez, são quase sempre subornados, exibem-se o mundo atrás das grades e os porões da sociedade de consumo, autoritária e viciada. Suas instituições vão sendo exibidas como ruína; família, escola, prisão, Estado, nenhuma cumpre a função a que se propõe idealmente.

O autor configura-se como vários enunciadores: filho amoroso ou revoltado, jovem em busca de sexo, ladrão contumaz, leitor e escritor crítico. Como filho ou aluno, incorpora as classificações que lhe foram impingidas desde cedo:

Dona Eida, minha mãe, dizia que até os seis anos eu era um santo. Meu pai, seu Luiz, dizia que eu era débil mental.

$(\ldots)$

Depois, fui para a escola. Dizem que de santo virei diabo. Lembro da primeira professora, de régua em punho, exigindo disciplina. E não obtinha, pelo menos não de mim. Enfiava a régua sem dó, ao menos descuido. Odiei escola, odiei professores. (MENDES, 2009, p.9)

Sua formação se dá com a incorporação da bastardia que marcara sua origem e regia sua vida de vítima matável, sem ter quem o defendesse, com exceção da mãe e da avó. Sexo e violência associamse na trajetória do "pequeno marginal". Configuram-se assim diferentes formas de prisão: a casa da família e a escola, em seu papel de reprimir e controlar: "Minha casa era o inferno, e meu pai o diabo a me esperar com o tridente em brasa para me espetar. (MENDES, 2009, p.27).

O corpo começa a ser moldado pela violência: "Quando cheguei em casa, meu pai me chamou no quarto, trancou a porta e começou a bater. Bateu, bateu, cansou, descansou, tornou a bater, bater, sem parar.” (MENDES, 2009, p.35)

Esse recurso de reiteração da ação repete-se no livro evidenciando a contingência do corpo. $\mathrm{O}$ sonho de liberdade, indiciado por sexo, drogas e rock and roll - "Meu sonho era ser malandro, daqueles que saíam no jornal" (p.56) - é interrompido com a força do cinto do pai, e depois dos instrumentos de tortura dos policiais:

Despiram-me inteiramente. Passaram panos, tipo faixa, pelos meus braços e pernas. Estávamos em uma sala minúscula, cheia de pneus e bicicletas velhas. Enquanto amarravam- 
me feito um porco, já comecei a chorar, estava desesperado, não sabia o que iam fazer comigo, só sabia que ia doer. Passaram um cano de ferro por trás de meus joelhos. Quando ergueram o cano, fiquei pendurado nele feito um frango assado. Colocaram as pontas dos canos sobre duas escrivaninhas velhas, de modo que fiquei no espaço vazio entre ambas, pendurado. (MENDES, 2009, p. 59).

A primeira experiência do choque elétrico vai se repetir ao longo do tempo na prisão, imprimindo, na narrativa, sensações corporais e psíquicas:

Então veio o choque. Denso e longo como uma cobra que deslizava sobre meus nervos. A sensação era de que me arrancavam as tripas pelo pé, se é que é possível tal sensação. Dor inenarrával, parecia que os fios entravam em minha carne e se grudavam no osso. Havia mesmo um cheiro de carne queimada no ar. (MENDES, 2009, p.60).

As várias imagens de animais são recorrentes: porco, frango, cobra, exibindo de forma crua o controle corporal e mental de um pelo outro. O olhar do delegado e dos agentes policiais repercute o olhar do panóptico foucaultiano no exercício do poder do Estado:

O delegado, gordão e barbudo, parecendo o João Bafo de Onça do gibi, observava. Seus olhos eram sinistros. Brilhavam, cintilando, no meio de toda a gordura que era sua cara. Eu o via no relance da lucidez, entre uma dor e outra. (MENDES, 2009, p.61) .

Entre sessões de tortura, sangue e dor, forma-se o prisioneiro, que entra e sai das instituições para menores e das penitenciárias em um movimento reiterativo de busca de liberdade, transgressões e castigos. Manifesta-se a consciência de um lugar de fala delineado por um período de exceção: "Tortura era uma instituição no país, praticada nos mais altos escalões de nação. Não acreditávamos em justiça. Quem iria se importar conosco?” (MENDES, 2009, p.100).

Ora violento e revoltado, ora solidário e justo, o narrador mostra a força do código do crime, persegue uma identidade, que se esfacela como seu corpo vitimado, quase suprimido:

Apanhei, apanhei, chorei, implorei que me matassem mas que não me batessem mais. Defequei, urinei, invonluntariamente, a sala ficou a maior fedentina. Passaram minhas fezes em minha boca e batiam, batiam, sem parar sem dar descanso. As pernas doíam como se o cano estivesse entrando nelas. O choque me chocoalhava todo e com o tempo foi deixando de fazer efeito.

\section{$(\ldots)$}

Devidamente torturado e arrastado, voltei para o xadrez, cheirando a merda e mijo. (MENDES, 2009, p.336).

O corpo escatologicamente apresentado faz-se metonímia da sociedade ali mencionada direta e indiretamente:

Estávamos cientes de que aqueles que nos barbarizaram o fizeram em nome de uma sociedade. Uma sociedade que nos repelia, brutalizava, segregava, e que quase nos destruía. E o pior: uma sociedade que precisava dessas monstruosidades para se manter. A tortura era uma instituição social.

Se estivéssemos em um país menos demagógico e mais civilizado, talvez recebêssemos a pena de morte. Nós seríamos, provavelmente, condenados à morte. Poderia até ser justo. Mas em nome dessa justiça, teríamos de ter recebido um tratamento que respeitasse as condições existenciais humanas em nossa infância e adolescência. (MENDES, 2009, p.346). 
É bom lembrar que, no período da escrita dessa obra, o Brasil atravessava a ditadura civil-militar instalada em 1964, o que torna mais explícita sua crítica social e política, o que não significa que a questão da violência na prisão e dos problemas sociais tenha sido enterrada com o fim do período de exceção. O texto de Mendes exibe o corpo decomposto do prisioneiro que aponta para a abjeção do corpo social: "O Instituto era apenas uma vitrine que o Estado ditatorial mostrava para a sociedade. E esta engolia, aliviando sua consciência de comunidade culpada.” (MENDES, 2009, p.155).

Larvas como as muquiranas invadiam o ambiente das prisões: "Eram minúsculos; os bichinhos saíam dos ovos, se disseminavam pelas roupas, crescendo e engordando com nosso sangue. Faziam parte da tortura e opressão geral." (MENDES, 2009, p.105). O corpo, misturado a excrementos e a insetos e larvas, expõe não apenas o ambiente infecto da prisão, mas a sociedade e suas relações de poder.

\section{Da sujeira à assepsia}

Une vie étrange m'envahit, une peine qui grandit, qui me noie, qui me tue. J'ai besoin d'aide. J'ai besoin d'aide. (Marie Gagnon, em Bienvenue dans mon cauchemar) ${ }^{2}$

Da violência física e suja das prisões brasileiras passa-se à violência asséptica das prisões canadenses, retratada por Marie Gagnon nas obras Bienvenue dans mon cauchemar (1999) e Lettres de prison (2002). As duas obras dizem respeito a duas diferentes prisões: le Tanguay (Montréal) et Joliette (Joliette - Québec). A primeira, agora fechada, é dada como mais precária e menos limpa que a segunda, uma prisão federal. É nessa, no entanto, que Marie Gagnon vê o que considera como grande violência, a assepsia da mente:

Tanguay abritatit des brutes véritables, mais aussi des filles que se sacrifiaient pour d'autres. Des êtres colorés. Ici, c'est tout gris. Là-bas, c'était dur, mais c'était vrai. J'y ai assisté à des scenes à se mettre à genoux et même à croire en Dieu. Ici, tout est tiède et faux. Tout est aseptisé. Geôle chrome, aussi froide que'une morgue. Et tous ces psycolo-intervenants qui vont psalmodiant leurs morbides sentences. (GAGNON, 2002, p.136)

É a própria autora que estabelece a relação direta entre essa prisão e seu país: "Le Canada est un pays de pharisiens nantis, hypocrites et sournois. Joliette, c'est pareil.” (GAGNON, 2002, p.137)4. Reagindo aos mecanismos da prisão e sua classificação dos prisioneiros, ela diz ainda que não quer ser a pessoa que a prisão deseja que ela seja:

La société m'a tourné le dos: elle m'a menottée, entravée, enfermée; elle a tripoté dans mon crane en vains tentatives d'en extirper l'original pour le remplacer par le commun. Eh bien! Mois aussi, je lui tourne les dos. Je fais "Fi" à cette société qui m'enchaine pour avoir la paix. Je me rends de plus en plus compte que je ne suis pas ici pour payer ma conduit passé, ni pour changer un comportement fautif, mais pour que je devienne comme les autres. Non, je me reprends: pas comme les autres, mais plutôt comme ce qu'il y de plus médiocre chez les autres. (GAGNON, 2002, p.88). ${ }^{5}$

2 Uma vida estranha me invade, um sofrimento que cresce, que me afoga, que me mata. Tenho necessidade de ajuda. Tenho necessidade de ajuda.

3 Tanguay abrigava verdadeiros brutos, mas também jovens mulheres que se sacrificavam pelos outros. Seres coloridos. Aqui, é tudo cinza. Naquela prisão, era duro, mas era verdadeiro. Nela eu assisti a cenas de se colocar de joelhos e até crer em Deus. Aqui tudo é morno e falso. Tudo é higienizado. Celas cromadas, frias como um necrotério. E todos estes "psico-palestrantes" que vão salmodiando suas mórbidas sentenças.

4 O Canadá é um país de fariseus ricos, hipócritas e dissimulados. Joliette é semelhante.

5 A sociedade virou as costas para mim: ela me algemou, me prejudicou e me adoeceu; ela mexeu com a minha cabeça em vãs tentativas de substituir o original pelo comum. Tudo bem! Eu também virei as costas para ela. Eu fiz "Fi” para esta sociedade que me acorrentou para ter paz. Eu me dei conta, aos poucos, de que eu não estou aqui para pagar minhas 
Ou ainda:

On m'ont cataloguée: 'antisociale grave'. Je prends ça comme un compliment. Non que je veille nuire aux autres: des actes illicites, je ne veux plus en commettre. Mais je ne veux pas ressembler à la citoyenne don't Joliette est le reflet. Elle est trop moche. (GAGNON, 2002, p.138)

\section{Escrita: entre a lei a e liberdade}

Como aproximar duas pessoas tão diversas, de dois países tão diversos? O primeiro é pobre, nascido na periferia de São Paulo, quase analfabeto. A segunda graduou-se em Letras e fez o mestrado, tornando-se leitora capacitada e crítica. O corpo do primeiro é massacrado, macerado, desmontado, mas reage e sobrevive a cada sessão de tortura. A segunda reage ao que considera o modelamento da mente e a assepsia da personalidade. Ambos são vítimas de dois tipos de violência, aquelas chamadas por Zizek de subjetiva e objetiva. A primeira, mais visível, seria a "exercida por agentes sociais, indivíduos maléficos, aparelhos repressivos disciplinados e multidões fanáticas" (ZIZEK, 2014, p. 24). A segunda sustentaria, invisivelmente, "a normalidade do nível zero contra a qual percebemos a contrapartida de uma violência subjetiva." (ZIZEK, 2014, p.18). Associa-se dessa forma à violência sistêmica, aquela "inerente a um sistema", "com formas mais sutis de coerção que sustentam as relações de dominação e de exploração” (ZIZEK, 2014, p.24). Ambos pertencem, assim, àquilo que Michel Foucault (1977) chama o corpo dócil dado como um tipo de observatório que permite melhor controle e manutenção da ordem social, política e econômica.

Não sem razão, Foucault, distinguindo criminoso e delinquente, associa a delinquência a um observatório político-social. Diz o autor:

Na realidade a utilização da delinquência como meio ao mesmo tempo separado e manejável foi feita principalmente nas margens da legalidade. (...) A delinquência, ilegalidade dominada, é um agente para a ilegalidade dos grupos dominantes. (FOUCAULT, 1977, p.247).

Os dois prisioneiros são, assim, parte da máquina prisional do Estado, que tem o poder de punir, controlando o corpo e a mente. Ao lado disso, outro ponto forte os une; ambos se fazem escritores, mesmo que com diferentes percursos. Narrando suas vidas sob forma de biografia ou de cartas dirigidas a pessoas mais próximas, eles resistem pela escrita, construindo-se como sujeitos perante o outro, inclusive aquele que não os conhece, mas os lê. Ambos dependem da mediação de terceiros; no caso de Mendes, faz-se relevante o papel de, entre outros, Eneida, uma estudante de Letras que lhe escrevia, do escritor Fernando Bonassi e do médico Dráuzio Varela, no reconhecimento da capacidade do novo escritor e na intervenção na publicação:

Falei sobre o livro engavetado. Ele quis conhecê-lo. Mais por amizade, assim para ter algo a oferecer ao novo amigo, mandei vir de casa o livro. O cara começou a ler, e os comentários eram de muito entusiasmo. Estava gostando de fato, dando valor ao meu texto. Não era só a história, mas o estilo também o agradava bastante. Fiquei imensamente contente por isso. Mas o amigo foi mais longe: queria que o livro fosse publicado. Me incentivou a que fizesse uma revisão do texto, do começo ao fim, atualizando-o, e se comprometeu a correr atrás de ajuda para publicá-lo. (MENDES, 2009, p.411).

atitudes do passado, nem para mudar um mau comportamento, mas para que eu me torne como os outros. Não, eu me corrijo: não como os outros, mas, sobretudo, como aquilo que há de mais medíocre nos outros.

6 Eles me catalogaram: « extremamente antissocial ». Eu tomei isso como um elogio. Não que eu queira prejudicar os outros: eu não quero mais cometer atos ilícitos. Mas eu não quero me parecer com uma cidadã, de que Joliette é o reflexo. Ela é muito feia. 
Maria Gagnon, por sua vez, corresponde com seu editor, Jean-Yves Soucy, da VLB Éditeur, a quem chama de amigo e cúmplice. Também esse editor lhe pede revisão do texto a ser publicado: “Tu me demandes de corriger mes Lettres de prison. Je peux bien essayer, mais acorde-moi du temps. Rien n'avance rapidement ici, en ce lieu aseptisé... pas même mas plume. (GAGNON, 2002, p.161) ${ }^{7}$

Em carta de 23 de abril de 2001, ela lhe reproduz a cena em que um policial the pergunta se é ela a escritora que ele tinha visto na televisão: "Comment quelqu'un qui a ton talent peut-il vivre de vols e vagabondage?” (GAGNON, 2002, p.82). ${ }^{8}$ Ao que ela responde, consciente da relação entre linguagem e experiência humana:

“- Merci pour le talent que vous me prêtez, monsieur, mais c'est justement sur la base de mon experiénce d'itinérante et de criminelle que je compte réaliser mon oeuvre littéraire si tant est que le mot oeuvre n'est pas ici déplacé." (Gagnon, 2002, p.82) ${ }^{9}$

Em ambos os casos, há parceria entre o intelectual e aquele que se encontra entre grades e muros, o que leva a um processo de linhas de fuga no seio da repressão. Não apenas a repressão propriamente dita, mas a impossibilidade da partilha da palavra.

Curioso verificar alguns exemplos de como a palavra circulava na cela forte da penitenciária brasileira por meio do encanamento dos vasos sanitários:

Trouxe o recado de que o Carlão estava dizendo para que eu tirasse a água da privada para ligar o telefone, queria conversar comigo. Explicou que o Carlão morava em frente e que o encanamento das privadas era um canal de ligação, de comunicação. (MENDES, 2009, p.372).

Era o telefone, nosso fétido veículo de comunicação. O cheiro era terrível, era preciso ter estômago. (MENDES, 2009, p.374).

Essa palavra ligada à escatologia humana busca superar distâncias, dentro e fora da prisão. Da mesma forma a palavra na prisão asséptica tem dificuldades de circular. A palavra "murs" é incessantemente repetida nos dois livros de Marie Gagnon, como os paredões e as grades mencionadas por Mendes, ao que se acrescentam os termos referentes à cor cinza e ao frio que mais marcam seu processo escritural:

J'ai besoin d'air. J'ai peur de m'incruster entre ces murs, de m'y fondre, qu'on me confonde avex eux. Ma peau deviendra-t-elle aussi froide que le ciment? Mon coeur, aussi dur? $(\text { GAGNON, 1997, p.54) })^{10}$

A essa imagem, junta-se a da ausência de ar, da dificuldade de respiração, como no poema "Murs":

Fatiguée des murs

Partout des murs

Encore des murs

Même! Um plafond de murs

D'où suintent voix et cris

Et pire... des murmures

Pas de silence, que des bruits

\footnotetext{
7 Você me pede para corrigir minhas Cartas da prisão. Eu posso tentar, mas me dá um tempo. Nada acontece rapidamente aqui, neste lugar higienizado.... nem minha pluma (caneta).

8 Como alguém que tem o seu talento pode viver de roubos e vagabundagem?

9 Obrigada pelo talento que o Senhor me concede, mas é justamente baseado em minha experiência como itinerante e criminosa que eu pretendo realizar minha obra literária, caso o nome obra não seja inapropriado aqui.

$10 \mathrm{Eu}$ preciso de ar. Eu tenho medo de ficar incrustada entre estes muros, de me fundir neles, que me confundam com eles. Minha pele se tornará tão fria quanto o cimento? Meu coração também endurecerá?
} 
J'étouffe, un soupir

Laisser-moi dormir! (GAGNON, 1997, p.65) ${ }^{11}$

Mais do que isso, mais do que dormir, Marie anseia se fundir ao muro, sair de si, não rumo ao outro, mas ao não-ser:

Je me suis assise dans mon lit, dans la position du lotus, puis j’ai fixé le mur. Durant dix minutes, quinze minutes, une demi-heure, je ne sais pas. Je me dédoublais. J'était hors de mon corps. Je ne sentais même plus la vie dans mon coeur. (GAGNON, 1997, p.85).

Ou ainda:

Mais si, un instant, j'ai pu oublier mon corps, pourrai-je parvenir à oublier mon essence humaine; mes désirs, mes passions, mes besoins peuvent-ils effacés? Je tends vers l'absolu, vers le non-être. J'aimerais disparaître. Les autres me fatiguen. (GAGNON, 1997, p.85) ${ }^{12}$

Paradoxalmente, nesse anseio para o nada, como forma de respiração, de busca do sopro vital, a palavra é pintada no muro da prisão e do corpo, como se pode ver no poema "Mot":

Elle chiale l'ombre épaisse et grotesque

Sur les murs de Tanguay, presque

D’une bave imbécile, une fresque. (GAGNON, 1997, p.61) ${ }^{13}$

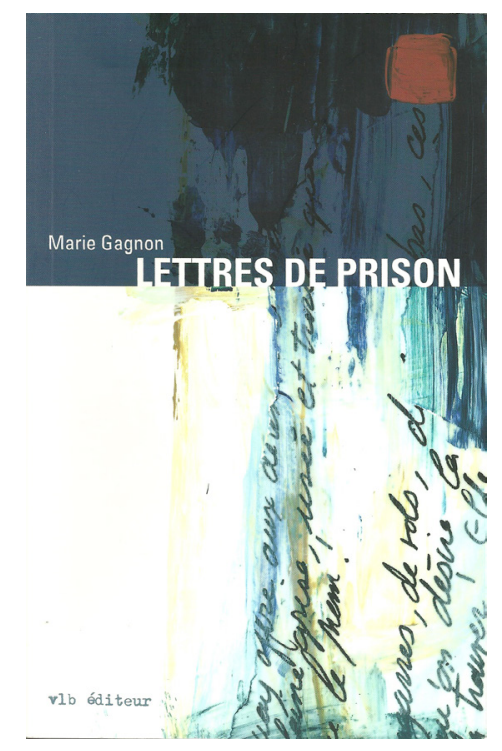

11 Cansada dos muros

Por toda parte muros

Ainda muros

De fato! Um teto de muros

De onde escoam vozes e gritos

E pior.... sussurros

Não há silêncio, só barulhos

Eu me sufoco, um suspiro

Deixem-me dormir!

$12 \mathrm{Eu}$ me assentei na minha cama, na posição de lótus, então, eu fixei o olhar no muro. Durante dez minutos, quinze minutos, uma meia-hora, eu não sei. Eu me dupliquei. Eu estava fora do corpo. Eu não sentia nem mesmo a vida em meu corpo.

Mas se, num instante, eu pude esquecer meu corpo, poderia eu chegar a esquecer minha essência humana, meus desejos, minhas paixões, minhas necessidades poderiam ser apagadas? Eu me aproximo do infinito, em direção ao não-ser. Eu amaria desaparecer. Os outros me cansam.

13 Ela chora a sombra espessa e grotesca

Sobre os muros de Tanguay, quase

De uma baba imbecil, um afresco. 
Assim como Mendes declara que a escrita o ajudou a reviver os acontecimentos e a pensar sobre eles, tornando-se uma necessidade: - "A intenção é escrever sempre e para sempre" (MENDES, 2009, p.409) -, Marie agrega sua identidade à escrita: "Je ne me sens d'aucune ville, d'aucun pays, d'aucun groupe social. Ma contrée, c'est l'écriture; mon village, les mots. (GAGNON, 2002, p.80) ${ }^{14}$

Marie, sempre se sentindo dividida em duas, ressalta a força da palavra mesmo no pesadelo, como no poema "Manque":

\author{
Tout de travers \\ Même en ce cauchemar \\ Où la main tremble d'écrire \\ J'écris encore, comme on soupire. \\ (GAGNON, 1997, p.145) ${ }^{15}$
}

Pode-se perguntar, porém, se esse exercício da escrita em busca de liberdade, de cores, de sons, como uma forma de pertencimento, é suficiente para a busca democrática da construção identitária. Antes de discorrer sobre isso, porém, há que se notar, com Zizek (2014), uma outra forma de violência, a simbólica, que se estrutura na própria linguagem. Isso porque, como bem mostra o autor, a despeito de fundamentar a condição humana, ou até por isso mesmo, a linguagem não está isenta da violência. Analisando a linguagem como condição da não violência postulada por outros autores, inclusive Hannah Arendt, o autor afirma:

(...) a própria linguagem, o meio por excelência da não-violência e do reconhecimento mútuo, implica uma violência incondicional. Em outras palavras, é a própria linguagem que impele o nosso desejo para além dos limites convenientes, transformando-o num 'desejo que comporta o infinito', elevando-o a um impulso absoluto que nunca poderá ser satisfeito. (ZIZEK, 2014, p.62).

Ao concluir sua reflexão feita com a ajuda da psicanálise, Zizek se posiciona, referindo-se ao que chama "o abismo do próximo":

Embora possa parecer que exista aqui uma contradição entre o modo como o discurso constitui o próprio núcleo da identidade do sujeito e a idéia desse núcleo como um abismo insondável para além da 'barreira da linguagem', há uma solução simples para o aparente paradoxo. A 'barreira da linguagem' que me separa para sempre do abismo de outro sujeito é simultaneamente aquilo que abre e que mantém esse abismo - o próprio obstáculo que me separa do Além - é aquilo que cria a sua imagem. (ZIZEK, 2014, p.67).

De qualquer forma, a linguagem seria o próprio espaço limiar de que fala Agamben $(2004,2007)$, pois é nela que, ao se constituir como sujeito frente ao outro, o homem exibe sua fratura incondicional.

Agamben retoma o conceito de biopolítica de Foucault, e, tentando dar sequência ao pensamento do autor francês morto, mostra como "o Estado assume e integra em sua esfera o cuidado da vida natural dos indivíduos", e como ele mesmo, se utiliza das "tecnologias do eu, através do qual se realiza o processo de subjetivação que leva o indivíduo a vincular-se à própria identidade e à própria consciência e, conjuntamente, a um poder de controle externo." (AGAMBEN, 2007, p.13). É então que o filósofo italiano se pergunta qual seria o ponto de interseção "em que técnicas de individuação e procedimentos totalizantes se tocam?” (AGAMBEN, 2007, p.13).

14 Eu não me sinto de nenhuma cidade, de nenhum país, de nenhum grupo social. Minha terra, é a escrita; minha cidade, as palavras.

15 Tudo errado

Mesmo neste pesadelo

Onde a mão treme ao escrever

Eu escrevo ainda, como se suspira. 
Os estudos de Agamben vêm se indagando sobre o expurgo da vida nua, da zoé, do seio da vida na pólis. Em vista disso, pode-se perguntar: Como se configura essa vida nua, a vida matável e insacrificável do homo sacer na vida da prisão de Mendes e Marie Gagnon? Como se situa a questão no uso da escrita como forma de resistência? Essa escrita rasurada de Mendes e Marie Gagnon, que exibe mais do que sua condição de prisioneiros e mais do que a prisão como metonímia da sociedade que a sustenta, exibiria a própria condição do homem frente a si mesmo e frente ao outro.

Por isso, vale lembrar Rancière na sua postulação de que "a escrita é indissoluvelmente, duas coisas em uma: é o regime errante da letra órfã cuja legitimidade nenhum pai garante, mas é também a própria textura da lei, inscrição imutável do que a comunidade tem em comum." (RANCIÈRE, 1995, p.9).

A palavra do prisioneiro encena duplamente tal condição da escrita. Isso porque essa escrita arma o jogo entre a dessubjetivação e a subjetivação, a insistência em se ver atuando no mundo, em um movimento da consciência que marca o ser humano, visível sobretudo em situações-limite. As próprias palavras de Mendes, em seu jogo entre os artigos definido e indefinido frente à expressão "ser humano" já são reveladoras dessa situação:

Não é lá dessas histórias muito edificantes, até muito pelo contrário, mas quem se der ao trabalho de ler, e tomara que sejam muitos, vai sentir que é apenas a história de um ser humano." (...) Mas acho que consegui entender um pouquinho desse tumulto, desse aparente caos e loucura que é o ser humano. (MENDES, 1999, p.415. Grifos acrescentados.) 


\section{Referências}

AGAMBEN, Giorgio. Estado de exceção: homo sacer II. Trad. Iraci D. Paleti. São Paulo: Boitempo, 2004.

AGAMBEN, Giorgio. Homo sacer: o poder soberano e a vida nua. Trad. Henrique Burigo. Belo Horizonte: Editora da UFMG, 2007.

ARENDT, Hannah. Acondição humana. Trad. Roberto Raposo. Rio de Janeiro: Forense Universitária, 2001.

FOUCAULT, Michel. Vigiar e punir: história da violência nas prisões. Trad. Lígia Vassalo. Petrópolis: Vozes, 1977.

GAGNON, Marie. Bienvenue dans mon cauchemar. Montréal: vlb éditeur, 1997.

GAGNON, Marie. Lettres de prison. Montréal: vlb éditeur, 2002.

MENDES, Luiz Alberto. Memórias de um sobrevivente. São Paulo: Companhia das Letras, 2009.

MENDES, Luiz Alberto. Às cegas. São Paulo: Companhia das Letras, 2005.

MENDES, Luiz Alberto. Confissões de um homem livre. São Paulo: Companhia das Letras, 2015.

RANCIÈRE, Jacques. A partilha do sensível: estética e política. Trad. Mônica Costa Netto. São Paulo: Editora 34, 2009a.

RANCIÈRE, Jacques. Políticas da escrita. Trad. Raquel Ramalhete. Rio de Janeiro: Editora 34, 1995.

ZIZEK, Slavoj. Violência: seis reflexões laterais. Trad. Miguel Serras Pereira. São Paulo: Boitempo, 2014. 